\title{
Radiation as a Risk Factor for Cardiovascular Disease
}

\author{
John E. Baker, ${ }^{1-3}$ John E. Moulder, ${ }^{4}$ and John W. Hopewell ${ }^{5}$
}

\begin{abstract}
Humans are continually exposed to ionizing radiation from terrestrial sources. The two major contributors to radiation exposure of the U.S. population are ubiquitous background radiation and medical exposure of patients. From the early 1980s to 2006, the average dose per individual in the United States for all sources of radiation increased by a factor of $1.7-6.2 \mathrm{mSv}$, with this increase due to the growth of medical imaging procedures. Radiation can place individuals at an increased risk of developing cardiovascular disease. Excess risk of cardiovascular disease occurs a long time after exposure to lower doses of radiation as demonstrated in Japanese atomic bomb survivors. This review examines sources of radiation (atomic bombs, radiation accidents, radiological terrorism, cancer treatment, space exploration, radiosurgery for cardiac arrhythmia, and computed tomography) and the risk for developing cardiovascular disease. The evidence presented suggests an association between cardiovascular disease and exposure to low-to-moderate levels of radiation, as well as the well-known association at high doses. Studies are needed to define the extent that diagnostic and therapeutic radiation results in increased risk factors for cardiovascular disease, to understand the mechanisms involved, and to develop strategies to mitigate or treat radiation-induced cardiovascular disease. Antioxid. Redox Signal. 15, 1945-1956.
\end{abstract}

\section{Introduction}

I ONIZING RADIATION is any electromagnetic wave or particle that can remove an electron from an atom or molecule of the medium through, which it is propagating. The basic unit used to measure absorbed dose from ionizing radiation is the gray (Gy), defined as 1 joule of initial energy per kilogram of tissue (91a). The biological effects per unit of absorbed dose (Gy) differ with the type of radiation, so that a weighted quantity called the "effective dose" is used, termed the sievert (Sv) (91a). For X-rays and $\gamma$-rays, $1 \mathrm{~Sv}$ equals $1 \mathrm{~Gy}$, but for other types of radiation this is not true (e.g., 1Gy of high-energy protons equals $10 \mathrm{~Sv}$ and $1 \mathrm{~Gy}$ of alpha particles equals $20 \mathrm{~Sv}$ ) (91a). All forms of life are constantly exposed to ionizing radiation from both terrestrial and cosmic sources. The major contributors to the exposure of the U.S. population from ionizing radiation are from ubiquitous background radiation and medical exposure of patients (Fig. 1). From the early 1980s to 2006, the average annual effective dose per individual in the U.S. population from all sources of radiation increased by a factor of $1.7-6.2 \mathrm{mSv}$, with the increase being almost entirely due to the growth of relatively high-dose medical imaging procedures using $\mathrm{X}$-rays and radionuclides. This review dis- cusses evidence that exposure to ionizing radiation increases the risk of cardiovascular disease.

\section{Sources of Cardiac Radiation Injury}

\section{Atomic bomb}

The radiation from the Hiroshima $\left({ }^{235} \mathrm{U}\right)$ and the Nagasaki bombs $\left({ }^{239} \mathrm{Pu}\right)$ was comprised of neutrons and $\gamma$-rays, resulting in an absorbed dose of up to $4 \mathrm{~Gy}$ in survivors. Neutrons account for only $1 \%-2 \%$ of the total radiation dose received by the survivors of the Hiroshima atomic bomb (although after accounting for their greater biological effectiveness relative to $\gamma$-rays, the proportion of the total dose becomes $10 \%-20 \%$ ) $(80 \mathrm{a}, 86)$. The risk of developing cardiovascular disease after whole-body exposure to radiation has been demonstrated in the Japanese atomic bomb survivors. Mortality from myocardial infarction $>40$ years after radiation exposure was significantly increased in people who had received an acute single dose of 1-2 Gy (70). The risk of death from heart disease increased by $17 \%$ per Gy after whole-body irradiation doses in the range $0-4 \mathrm{~Gy}$, mostly from $\gamma$-rays. Approximately $16 \%$ of the 117 myocardial infarctions seen in exposed persons could be attributed to radiation exposure from the atomic

\footnotetext{
${ }^{1}$ Division of Cardiothoracic Surgery and ${ }^{2}$ Department of Pharmacology and Toxicology, Medical College of Wisconsin, Milwaukee, Wisconsin.

${ }^{3}$ Children's Research Institute, Children's Hospital of Wisconsin, Milwaukee, Wisconsin.

${ }^{4}$ Department of Radiation Oncology, Medical College of Wisconsin, Milwaukee, Wisconsin.

${ }^{5}$ Green Templeton College and Particle Therapy Cancer Research Institute, University of Oxford, Oxford, United Kingdom.
} 


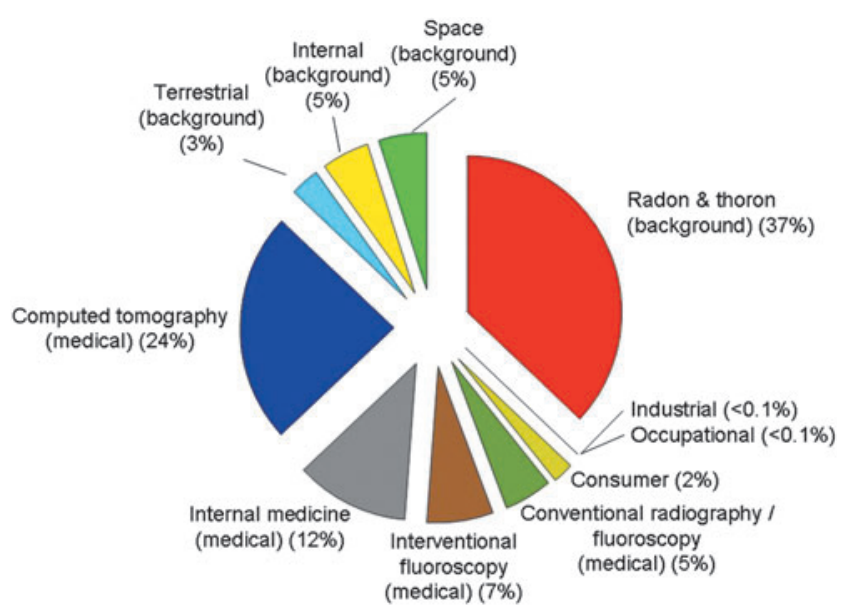

FIG. 1. Percent contribution of various sources of exposure to the total effective dose per individual in the U.S. population $(6.2 \mathrm{mSv})$ for 2006 . Reprinted with permission from the National Council on Radiation Protection and Measurements, http://NCRPonline.ord.

bomb, most of which could be attributed to doses >1 Gy (99). A recent report indicates that radiation increases the rates of heart disease in the atomic bomb survivors at moderate dose levels (mainly 0.5-2 Gy) (Fig. 2) (79); however, the degree of risk associated with the lower doses of radiation is unclear. Stroke and heart disease combined now account for about one-third the number of radiation-associated excess deaths in atomic bomb survivors compared with cancer (79).

\section{Radiation accidents}

The accident at the Chernobyl nuclear power plant in 1986 was the most severe accident in the history of the civilian nuclear power industry. The initial radiation exposure originated from $>40$ different radionuclides, notably in the first 10 days after the accident. The most significant of these were

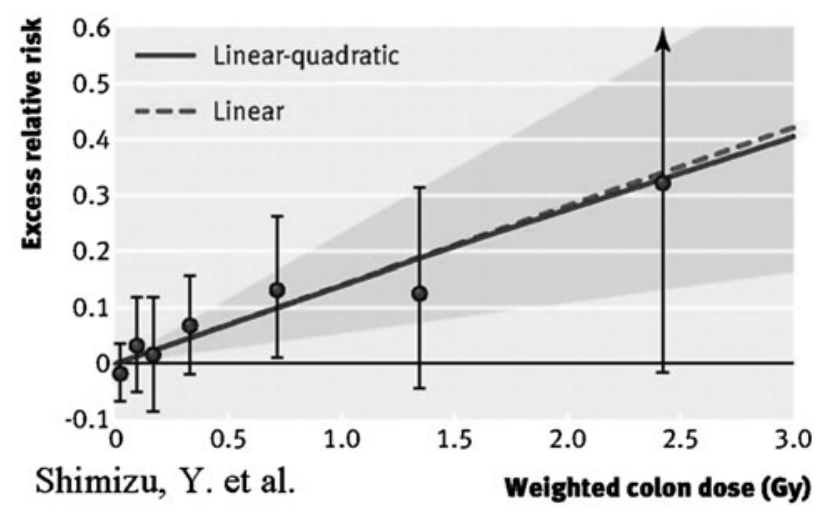

FIG. 2. Radiation dose-response relation (excess relative risk) for death from heart disease, showing linear and linear-quadratic functions. Shaded area is $95 \%$ confidence region for fitted linear line. Vertical lines are $95 \%$ confidence intervals for specific dose category risks. Point estimates of risk for each dose category are indicated by circles. Reproduced from Shimizu et al. (79) with permission from BMJ Publishing Group Ltd. iodine $\left({ }^{131} \mathrm{I}\right)$, caesium $\left({ }^{137} \mathrm{Cs}\right)$, and strontium (particularly ${ }^{90} \mathrm{Sr}$ ). ${ }^{131} \mathrm{I}$ produces $\beta$ - and $\gamma$-ray emissions, ${ }^{137} \mathrm{C}$ s produces $\gamma$ rays, and ${ }^{90} \mathrm{Sr}$ produces $\beta$-emissions. In 1986, the average dose to $>300,000$ recovery workers, "liquidators," was nearly $150 \mathrm{mSv}$, and >350,000 other individuals received doses $>10 \mathrm{mSv}$ (71a). Increased risk of death from cardiovascular disease in highly exposed individuals is possible, and longterm follow-up studies are needed to determine the extent that cardiovascular disease is manifest in this population. Injury to the cardiovascular system is present early after accidental total body irradiation (TBI). In a study of 110 highly exposed individuals, 1-10 days after radiation exposure with injury to the hematopoietic system and many with severe skin lesions, 20 patients (18\%) exhibited injury to the cardiovascular system, and mostly as heart failure (38).

\section{Radiological terrorism}

There is an urgent need to understand the extent of injury likely to develop to vital organs such as the heart after radiation exposure from a terrorist attack or a nuclear power plant accident, to define the mechanisms underlying the injury, and to devise treatment strategies using currently available pharmaceuticals and nutriceuticals. The International Atomic Energy Agency (IAEA) reports that there have been 175 cases of trafficking in nuclear materials, including 18 cases involving highly enriched uranium or plutonium, as well as 201 cases of trafficking in other radioactive material. According to an article in The Lancet (44), "a terrorist organization could explode a crude weapon made of stolen plutonium with a yield of 0.1-20 kilotons"; in comparison, the bomb used on Hiroshima had a yield of $\sim 15$ kilotons. A study published in the British Medical Journal (41) has estimated that a small 12.5-kiloton nuclear bomb detonated in New York City would cause 50,000 deaths immediately with an additional several hundred thousand cases of "radiation sickness." Another potential nuclear threat is that of an attack or accident at a nuclear power plant or waste storage facility. An equal concern is the vulnerability of spent fuel pools that can contain 20-30 times more radioactive material than the reactor core and are in buildings not nearly as strong as those that house the reactors.

The extent to which exposure to $10 \mathrm{~Gy}$ TBI, a potentially survivable dose in a radiation accident or radiological terrorism event (22), could result in injury to the cardiovascular system is unknown. In this situation, the entire body rather than a single organ such as the heart would be exposed to a single, possibly heterogeneous dose of radiation. Evidence that TBI injury may be a cardiovascular risk factor comes from longitudinal studies of Japanese atomic bomb survivors. In this population, mortality from cardiovascular disease is significantly increased after $>40$ years after single dose exposure of 1-2 Gy to the whole body $(70,99)$. Radiation therapy used in the treatment of benign and malignant disease has also been linked to the development of cardiovascular disease. For example, radiation therapy for the treatment of peptic ulcer disease is correlated with an increased mortality from coronary heart disease (17). Radiotherapy treatment for breast cancer is associated with an increased risk of cardiovascular disease (45), and for Hodgkin's lymphoma it is associated with an increased risk of myocardial infarction (87). In these clinical studies, nonthoracic organs were the specific target of 
the treatment, and yet cardiovascular disease was a significant cause of long-term morbidity or mortality (59).

In a radiological terrorism or nuclear accident event, children would account for a significant portion of the population affected and thus studies are needed to determine whether a single exposure to $10 \mathrm{~Gy}$ TBI in the child might increase the risk factor for development of cardiovascular disease and damage to heart morphology and ventricular function. Evidence from the clinical use of radiation to treat children with cancer supports the existence of an increased risk of cardiac injury. Exposure to 10 Gy TBI in association with bone marrow transplantation in the treatment of children for leukemia results in immediate and delayed cardiac abnormalities manifest as decreased left ventricular ejection fraction and abnormal electrocardiogram $(32,68)$, supporting the notion that radiation exposure in children can lead to cardiac dysfunction during development into adulthood. However, these patients with leukemia also receive chemotherapy, which may contribute to the cardiotoxicity of the overall treatment. Further studies are needed to understand the molecular events involved in radiation-induced cardiovascular disease.

\section{Space exploration}

Human space exploration missions to a Lunar and Martian environment are actively being planned. These missions will require humans to live for prolonged periods outside the protection provided by the Earth's atmosphere and geomagnetic field. The terrestrial environment effectively shields humans against exposure to deep space radiation. On the Earth most human radiation exposures (medical and natural background) are from low-linear-energy transfer photons (low LET X- and $\gamma$-rays), low-energy $\alpha$-particles from radon, and $\gamma$-rays and neutrons in the survivors of atomic bomb explosions. Throughout any Lunar and Martian mission, radiation exposure will be a major hazard for humans. Understanding the long-term effects of radiation on human health is essential before undertaking space exploration for extended periods. Space radiation is very distinct from the radiation exposure on the Earth. During exploratory missions to the Lunar and Martian environments, astronauts will be exposed to heavy ions and energetic protons in galactic cosmic rays (GCR) and lower-energy protons in solar particle events (SPE), plus secondary protons, neutrons, and heavy ions produced in the spacecraft shielding particle type. Based on estimated fluence rates (number of atomic nuclei per unit area), protons are by far the most abundant. However, heavy ions have much greater ionization potential and hence are major contributors to total equivalent physical dose, with heavy iron ions being the most important contributor (31). Providing shielding in spacecraft has excessive costs and will not eliminate GCRs. The risk of developing degenerative diseases such as coronary heart disease from radiation exposure during and after deep space exploration from GCR and SPE needs to be defined before attempting exploratory missions to the Lunar and Martian surfaces. As degenerative cardiovascular disease takes extended periods to develop, the risk to the astronaut remains after the astronauts return to the Earth. Radiation dose limits need to be established that will limit the risk of degenerative cardiovascular disease from occupational radiation exposure in space to an acceptable level.
A 1000-day exploratory mission to the Martian surface may require 400 days in deep space and 600 days on the surface of Mars (23). For men aged 40 at the time of the mission, the corresponding excess risk of death from radiation exposure is estimated to be between $\sim 1.3 \%$ and $13 \%$ (25). During the transit to Mars, the nucleus of every cell in the body may be traversed by a high-energy proton once every 3 days, and a helium ion once every 30 days $(24,26)$. On the assumption that the human body contains $\sim 10^{14}$ cells, at least $3 \times 10^{12}$ cell nuclei will be traversed by an ion of iron during the course of the mission (74). The resulting physical radiation dose incurred is estimated to be $\sim 0.4 \mathrm{~Gy}$, corresponding to $\sim 1.1 \mathrm{~Sv}$ (74). Exposure of mice to total physical doses of $0.2 \mathrm{~Gy}$ of ${ }^{20} \mathrm{Ne}$, $1.6 \mathrm{~Gy}{ }^{40} \mathrm{Ar}$, and $3.2 \mathrm{~Gy}$ of ${ }^{12} \mathrm{C}$ resulted in structural injury to the coronary vessels 15 months after irradiation manifest as smooth muscle cell degeneration, fibrosis, and extracellular deposition (101). A single physical dose of 0.1 or $0.2 \mathrm{~Gy}$ of ${ }^{56} \mathrm{Fe}$ ions to the orbital region of the mouse results in degenerative changes in the coronary arteries 15 months after irradiation (100). These findings suggest that exposure to ions of iron at fluence rates relevant to those that would be encountered in space exploration results in late cardiovascular injury. In addition, the observation that radiation of the brain may be responsible for causing remote injury in the heart supports recent findings that injury to the heart caused by 10 Gy TBI is indirect and likely caused by dysfunction of other organs, resulting in the export of factors that contribute to coronary sclerosis and cardiac ventricular dysfunction (6). Based on these estimates, it is likely that exposure to protons, helium, and iron ions during an exploratory mission to Mars could subsequently result in degenerative cardiovascular disease. Further studies are needed to define the risk for late cardiovascular disease after exposure to high atomic number, highenergy (HZE) ions, and protons at low fluence rates.

The physical dose needed to produce a biological effect from irradiation with a higher LET is lower when compared with $\gamma$-rays. Ions of iron and helium have a higher relative biological effectiveness than $\gamma$-rays. For humans, there is no information available as to the relative biological effectiveness of these particles in the heart. In studies on other organs, the relative biological effectiveness of high-energy heavy ions in mice and rats for carcinogenesis in skin and Harderian or mammary glands can be as high as $25-40$ after doses $<1$ Gy $(5,16,30)$. Thus, by extrapolation, the radiation dose from ions of iron, helium, and possibly protons needed to increase the risk factors for cardiovascular disease is likely to be considerably less than for $\gamma$-rays. Nontargeted, bystander effects may also increase the risk for degenerative cardiovascular disease at low doses. Studies are needed to determine the relative biological effectiveness of ions of iron, helium, and protons for increasing risk factors for cardiovascular disease at the low doses associated with space exploration.

\section{Cancer treatment}

There has been general recognition since the mid-1960s that high doses of radiation, administered as a consequence of the treatment of patients with cancer, can cause damage to the heart and pericardium (21). In the treatment of localized malignant disease, for example, Hodgkin's disease and carcinoma of the breast, the dose distribution to the heart is highly nonuniform. For example, in 50 consecutive patients 
treated for left-sided breast cancer using tangential fields in a single center in the United Kingdom in 2006, 44\% (22/50) received a dose of $>20 \mathrm{~Gy}$ to up to $5 \%$ of the total heart volume (88). The average maximum dose in this series was $30.7 \mathrm{~Gy}$ and the minimum $\sim 2 \mathrm{~Gy}$. An average mean heart dose of 2.3 Gy was quoted, but the biological significance of an average dose when the dose variation is so large is difficult to judge. Average maximum and minimum doses to the heart for patients treated with the same technique for cancer of the right breast were of the order of $2 \mathrm{~Gy}$. All of these doses represent total accumulated dose from fractionated irradiation, in this instance, a standard 15 fractions, given as 5 fractions/ week over 3 weeks. Based on the application of the linear quadratic model of cell survival [a model in which biological effect $E$ is a linear-quadratic function based on the number of dose fractions $(N)$ and the physical dose/fraction $(d)$, where $E=\left(d+\alpha \beta d^{2}\right) N d$; the $\alpha / \beta$ ratio is a tissue-specific constant for which a value of $2 \mathrm{~Gy}$ has been obtained from experimental studies of heart damage (75)], the maximum average dose quoted above would translate to a equivalent single dose of $\sim 10$ Gy. The minimum dose of $\sim 2$ Gy (left-sided breast cancer) and about 2 Gy (right-sided breast cancer) would remain unchanged because after the small doses/fraction associated with such a total physical dose, the linear component in the model predominates. Average heart doses are not applicable to such an analysis.

A difference in the risk of mortality from cardiovascular disease for patients treated with radiotherapy for left-sided versus right-sided breast cancer have been used as evidence of radiation-induced heart disease. A recent analysis of the extensive data from the U.S. Surveillance Epidemiology and End Result (SEER) cancer registries (28) has shown that for patients treated with radiotherapy, the mortality ratio (left sided vs. right sided) was 1.16 (95\% confidence interval [CI] 1.08-1.24; two-sided $p$-value $[2 \mathrm{p}]=0.00004)$ and that, furthermore, the increase in cardiac risk increased with time from diagnosis from $1.04(0.93-1.15)$ for $<5$ years, to $1.1(0.97-1.25)$ for 5-10 years, to 1.37 (1.14-1.64) 10-15 years, and 1.53 (1.251.86) for 15 years or more. The risk ratio for patients not treated with radiotherapy was not significantly different from 1.0. A similar trend has also been observed in an analysis of the cases from the trials included in the follow-up of the Early Breast Trialists' Collaborative Group (EBCTCG), where an excess mortality of heart disease of 1.27 (standard error 0.07 , $2 p=0.0001$ ) was quoted (19). In both of these studies, the variation in doses to the heart will be much more variable than those quoted earlier. This is because of the wide variation in the treatment methods used both in terms of the dose fractionation schedule and the orientation of the treatment fields. An indication of the likely variability was obtained from a reconstruction of heart doses for treatment schedules between 1950s and 1990s (89). Other breast cancer studies have also indicated an increased risk ratio of cardiovascular mortality after treatment for left-sided breast cancer of 1.1 (1.03-1.180) for all vascular disease and 1.13 (1.03-1.25) for Swedish women (27) and 2.1 (1.11-3.95) in a small population based study in Canada (67).

Evidence of cardiac disease developing in patients treated with mediastinal radiotherapy for Hodgkin's disease has come from a number of publications (83). It has been reported to account for $25 \%$ of all deaths that were not associated with Hodgkin's disease. Estimates of relative risk are, in general, in the range 2.2-3.1, although one study estimated it to be as high as $7.2(4)$. The dose distribution, like that for patients treated for breast cancer, was highly nonuniform.

One additional study quoted as evidence that radiotherapy causes an increased risk of cardiovascular disease involved a study of 1859 patients treated for a benign condition, peptic ulcer, between 1936 and 1965, with a similar number of patients suffering from the same disease treated by other means serving as control (17). The relative risk of mortality from cardiovascular disease was 1.24 (1.04-1.47) after $>10$ years and only 1.02 for $<10$ years. The relative risk also appeared to increase with the average total cardiac dose from unity after average dose of 0.1-1.9 Gy to 1.51 after 3.1-7.6 Gy. However, the mean peak dose in the beam assumed that $5 \%$ of the total heart volume also increased with the average dose from 7.6 to $18.4 \mathrm{~Gy}$, although as with the average dose there was considerable variation in the total dose in each of 4 dose ranges used for the analysis. These represent cumulative doses from fractionated irradiation using various machines, although typically $250 \mathrm{kVp}$ X-rays. Doses were given as $1.5 \mathrm{~Gy}$ daily fractions during one or two 6-14-day treatment courses. The objective was to give a total dose of 16-17 Gy to the stomach and with about $5 \%$ of the heart (the apex) in the irradiation field during treatment. These authors extensively discussed the relative importance of the high doses to a small volume as opposed to the much lower average, very homogeneous dose to the whole volume as the cause of the increased risk. This debate holds true for all the reported studies demonstrating an increased risk of mortality from heart disease after local radiotherapy for tumors adjacent to the heart. Perhaps only after the risk from relatively standardized total doses, fractionation schedules and treatment setups have been assessed will this debate finally be resolved. The observation that average doses, normally based on the cumulative dose from fractionated irradiation, are low and in the range estimated for the Japanese atomic bomb survivors may give a false sense of security, since unlike the dose in radiotherapy patients, the dose in these survivors is more likely to be much more uniform and associated with irradiation of the whole body.

Therapeutic whole-body irradiation results in a significantly more homogeneous dose to the heart. A safe, single, and effective dose is $10 \mathrm{~Gy}$ given at a low dose rate. This has proven to be the critical issue since too high a dose rate will result in fatal acute pulmonary complications. Total wholebody irradiation dose can also be increased to 12-15 Gy, given as six equal fractions twice/day over 3 days. The interval between the two fractions should be at least $6 \mathrm{~h}$, and dose rate is less important (69). Despite the clinical use of TBI for the treatment of a number of conditions, and in particular leukemia in childhood, there have been no systematic reports relating this treatment to delayed cardiac toxicity. Indeed in one report (58), toxicity related to TBI is implied because of the cardiac toxicity associated with the use of mediastinal irradiation used in the treatment of Hodgkin's disease in childhood. In a more recent systematic review (93) on the risk of morbidity and mortality from cardiovascular disease after radiotherapy for childhood cancer, no data sets related to the use of TBI are included. This lack of data may simply reflect the poor prognosis of patients treated using this particular modality or the lack of clarity in ascribing effects to radiation alone. Since bone marrow transplantation follows TBI, graft versus host disease and the use of chemotherapy are confounding factors. Two very recent reports deal specifically 
with the cardiovascular risk factors associated with the retreatment of childhood and adolescent cancers $(61,66)$, and some of the patients included received TBI. The hazard ratios associated with congestive heart failure were significantly increased but only after average heart dose of $\geq 15 \mathrm{~Gy}$, which is very unlikely to include TBI cases. On the other hand, the odds ratio (OR) associated with cardiovascular risk factors for adult survivors of childhood cancer was found to be higher (OR 5.5; 95\% CI 1.5-15.8) for those treated with TBI (61) compared with just chest and abdominal irradiation (OR 2.3; 95\% CI 1.2-2.4). Although not significant, this provides evidence for a trend toward a greater effect of TBI. The OR values for radiation exposure were greater than those for anthracycline use in treatment, but it should be noted that this study (61) only applied to patients who had been treated between 1970 and 1986 and who had survived for at least 5 years after diagnosis, and thus represents a long-term study of the type reported earlier for breast cancer patients. The cardiovascular risk factors for this study group were also clearly linked to the current age of patients, the OR being 1.0 for $<30$ year olds, rising to 8.2 for the +40 -year-old group.

As mentioned above, it is frequently assumed but as yet not totally proven, that the heart of children is more sensitive to radiation exposure than adults. However, there have been only a few studies published where both the follow-up of young and older patients have been compared $(51,57)$. In the earlier study, a total of 326 patients who had received mantle irradiation survived for over 3 years. Of these, 5.5\% had a morbid cardiac event related to coronary artery disease. The mean interval from radiotherapy to the event was 13.1 years (range 4.4-27 years). The mean age at the time of irradiation was 26.3 years (range 10-53 years). The observed to expected ratio of cardiac artery disease was 38.2 in patients treated under the age of 21 compared with only 2.8 in the group as a whole. The increased risk of cardiovascular events in patients treated with radiotherapy at the age of $<18$ years was 44.0 in the study by Lee et al. (57), compared with the overall risk in all patients of 7.0. Difference in the age structure of the two populations and the treatment techniques used may explain the differences between the two studies, but the overall trend is self-evident.

\section{Radiosurgery for cardiac arrhythmia}

Atrial fibrillation is the most common sustained cardiac arrhythmia and is associated with impaired quality of life and an increased risk of stroke and mortality. Radiofrequency ablation of arrhythmogenic cardiac lesions can injure normal tissue beyond the intended pathological territory. Recently, $\mathrm{X}$-rays have been used to target a local area of the heart associated with the genesis of atrial arrhythmias (78). A local dose of $25 \mathrm{~Gy}$ or larger created a lesion that altered the electrophysiology of the heart. Fibrosis and inflammatory infiltration, secondary to radiation, was present in the target area. Targeted lesion volumes were not reported. The concept of a noninvasive procedure to ablate cardiac arrhythmias is appealing. However, long-term consequences of using X-ray radiation in this setting are not well understood. Radiationinduced injury can take many years to become manifest, and the effects on surrounding tissues need to be defined. Further studies are needed to define the risk from local irradiation on developing cardiovascular disease.

\section{Diagnostic radiology}

The contribution of medical imaging to the exposure of the U.S. population is almost the same as background radiation ( $3.0 \mathrm{mSv}$ or $48 \%$ of that from all sources) (Fig. 1). This is due to major developments in the diagnosis and treatment of cancer and heart disease over the past 20 years, predominantly in the fields of computed tomography (CT), interventional radiology, and nuclear medicine. CT is a medical imaging method used to generate three-dimensional images of the inside of an object including the heart. Multiple X-ray scans are used to generate images. CT scanning involves larger radiation doses than conventional X-ray imaging procedures (12) and accounts for $17 \%$ of hospital departmental work load, but $70 \%$ $75 \%$ of the collective dose from medical radiation. During a CT session the heart may be subjected to two to three scans. In the last 20 years, technical improvements have lowered radiation dose in CT scanning. The relatively high dose of cardiac CT (10-15 mSv) as initially implemented using retrospective gating and intended wide application in the medical community caused controversy. Cardiac CT is now performed with prospective gating resulting in a dose reduction of $80 \%$ and an average patient radiation dose of 2 $4 \mathrm{mSv}$ (63). This compares to a cardiac nuclear medicine stress test with a dose approximating $7.5 \mathrm{mSv}$. Given improvements in scanner performance and, in particular, image reconstruction techniques, an average radiation dose of 1-2 mSv for cardiac CT scanning may be expected. This reduction in dose would be expected to decrease the risk for developing late cardiovascular disease. However, the longterm consequences of CT interventional radiology and nuclear medicine to the development of cardiovascular disease remain unknown.

\section{Radiation as the Cause of Late Cardiovascular Disease in Animals}

Further evidence that radiation causes cardiovascular disease comes from animal studies. Radiation either directly to the thorax or specifically to the heart $(18,37,55,56,103,104)$ will result in the development of injury after doses of $15 \mathrm{~Gy}$ and higher. A single exposure to 15-60 Gy exerts an adverse long-term effect on cardiovascular function in the rat, resulting in morphological degeneration (53), mechanical dysfunction (98), damage to the endothelium (9), and increased mortality (56). It has been suggested that radiation-induced cardiac injury is mediated by micro-vascular injury caused by inflammation and oxidative stress $(6,75,81)$, but further studies are needed.

The extent to which radiation affects the cardiovascular system is poorly understood. The effect of 10 Gy TBI on cardiac risk factors, coronary vasculature, and cardiac function in the WAG/RijCmcr rat has recently been determined.

From 20 days after TBI, a progressive increase in total serum cholesterol was seen. Low-density lipoprotein cholesterol progressively increased to a peak value of $82 \pm 8 \mathrm{mg} / \mathrm{dl}$ at 80 days compared with $13 \pm 3 \mathrm{mg} / \mathrm{dl}$ in unirradiated rats. There was also a transient increase in triglyceride levels 40 days after TBI, which then declined to values present in unirradiated rats by 100 days (Fig. 3).

Micro-CT showed a striking reduction in the density of the smaller diameter coronary vessels $(<50 \mu \mathrm{m}$ diameter) at 120 days after TBI (Fig. 4). The diameter of the epicardial arteries 

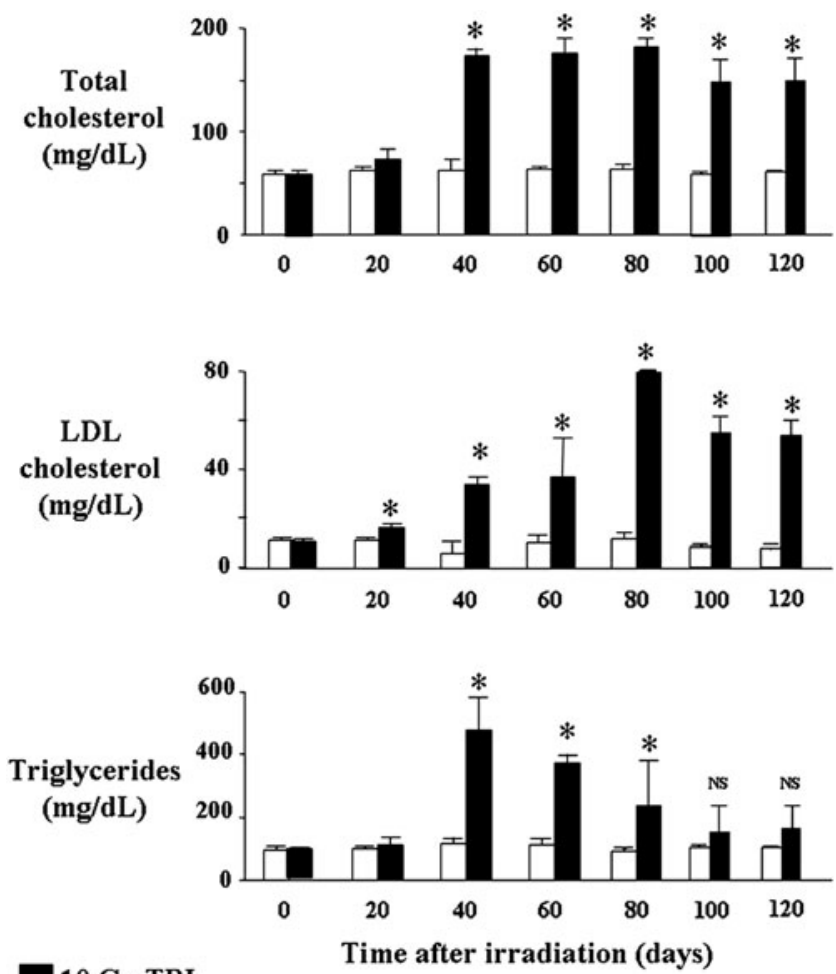

10 Gy TBI

\section{Age matched controls}

FIG. 3. Time-related changes in total cholesterol, lowdensity lipoprotein (LDL) cholesterol, and triglycerides after total body irradiation (TBI). Data shown as mean \pm $\mathrm{SD}, n=6$ /group. ${ }^{*} p<0.05,10$ gray (Gy) versus unirradiated controls. Reproduced from Baker et al. (6) with permission from Taylor \& Francis, Ltd. (www.tandf.co.uk/journals).

were unaffected by TBI. Three-dimensional reconstruction of the coronary network revealed a decrease in the smaller diameter penetrating vessels in $32 \%$ of the irradiated heart fields examined at random compared with the unirradiated controls.

Histological studies confirmed the CT findings seen in hearts 120 days after TBI showing sclerosis of intramural

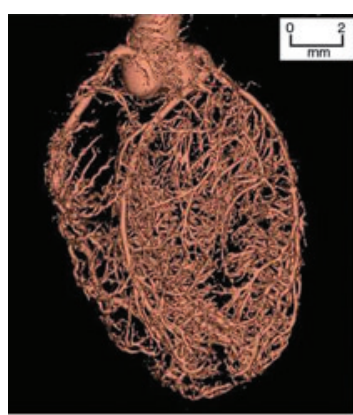

Control

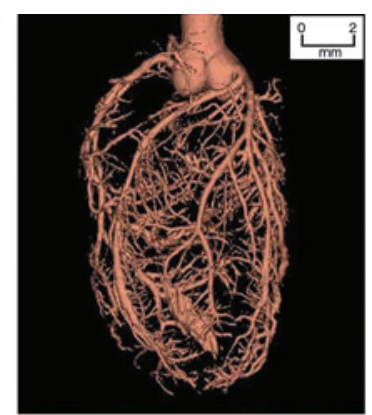

10 Gy TBI
FIG. 4. Computed tomography reconstruction of coronary arteries at $\mathbf{1 2 0}$ days after TBI, compared to age-matched control. TBI reduced the number of vessels of smaller diameter $(<50 \mu \mathrm{m}$ diameter $)$ but not the epicardial vessels. Reproduced from Baker et al. (6) with permission from Taylor \& Francis, Ltd. (www.tandf.co.uk/journals). coronary vessels. Affected vessels had partial to complete luminal sclerosis due to concentric laminar thickening of the vessel walls with accumulation of matrix material between layers of hyperplastic and vacuolated smooth muscle cells. The cardiomyocytes from TBI-treated hearts remained normal in appearance. Trichrome staining revealed peri-arterial fibrosis and irregular collagen deposition around the penetrating coronary vessels of irradiated hearts. Control hearts had symmetrical penetrating vessels with less collagen and fibrosis (Fig. 5).

Also after TBI, rats had significantly reduced global radial (Fig. 6) and circumferential strain compared to unirradiated controls as assessed by echocardiography. These changes represent significant biological injury and are an early sign of clinical heart failure. Thus, a single exposure to $10 \mathrm{~Gy}$ TBI was associated with the development of risk factors for cardiovascular disease, cardiac tissue degeneration, and cardiac dysfunction.

\section{Individual Radiation Sensitivity: Genetic and Gender Effects}

It is likely that in exposure to space radiation, there will also be genetic and gender differences in the patterns of injury. Genetic diversity and gender differences need to be assessed as risk factors for degenerative cardiovascular disease after simulated space irradiation.

Gender differences in risk factors for cardiovascular disease in astronauts exposed to deep space radiation are incompletely understood. Female mice have been reported to be more sensitive than male mice to the effects of ${ }^{56} \mathrm{Fe}$ ion irradiation (2-3 Gy) to the brain or hippocampal function (95). Female monkeys are more sensitive to the mortality effects of proton irradiation than males, with a dose effect occurring in the $0.25-1.13$ Gy range, compared with a dose effect in the range of 3.6-4.0 Gy in males (105). Gender differences also exist in susceptibility and progression of cardiovascular disease $(7,85)$. As the astronaut corps at NASA is comprised of males and females, there will be a need to determine the influence of gender on risk for degenerative cardiovascular disease resulting from space radiation.

Subjects with disease of genetic repair such as ataxia telangiectasia have greatly enhanced sensitivity to irradiation, and a greater sensitivity is also reported for subjects with scleroderma (20). It is likely that in astronauts exposed to space radiation, there will be genetic differences in the patterns of injury. In support of the notion of genetics as a factor influencing cardiovascular disease, one of us (John Hopewell) has shown that after local heart irradiation, cardiac output declined in Sprague Dawley rats and increased in Wistar rats (104). Selection of astronauts based upon the composition of an individual's genome may be a useful strategy to decrease risk factors for developing degenerative cardiovascular disease from radiation exposure associated with deep space exploration. Investigations are urgently needed to determine the mechanistic basis for these genetic and gender differences.

\section{Potential for Medical Countermeasures to Prevent, Mitigate, and Treat Radiation-Induced Injury}

There is an immediate need for a practical therapy to prevent, mitigate, and/or treat radiation-induced injury to the heart after irradiation (22). The U.S. National Institutes of 


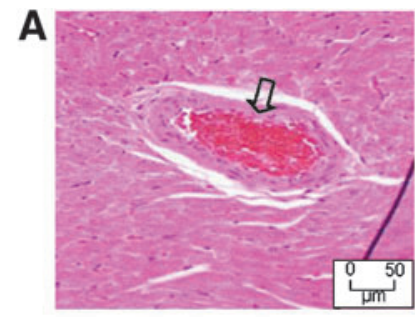

Control

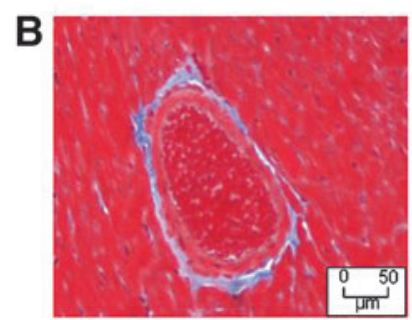

Control

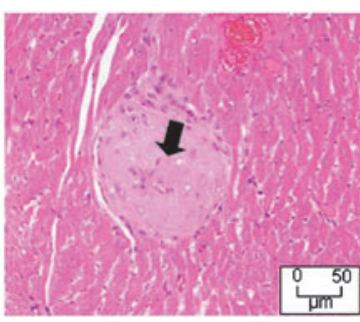

10 Gy TBI

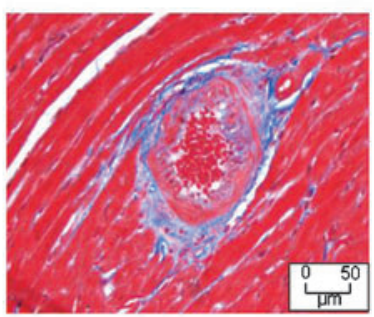

10 Gy TBI
FIG. 5. Morphological changes to the coronary vasculature at $\mathbf{1 2 0}$ days after $\mathbf{1 0}$ Gy TBI. (A) Heart sections, stained with H\&E, show vessel lumen completely blocked $(\rightarrow)$ as a result of myointimal proliferation 120 days after $10 \mathrm{~Gy}$ TBI. The lumen of a comparable vessel in an age-matched unirradiated heart is patent and contains red blood cells $(\Rightarrow)$. (B) Heart section, stained with Trichrome, showing increased peri-arterial fibrosis in small caliber coronary vessel 120 days after 10 Gy TBI compared with a comparable vessel in an age-matched control. Fibrosis appears as blue using trichrome staining. Reproduced from Baker et al. (6) with permission from Taylor \& Francis, Ltd. (www.tandf.co.uk/ journals).

Health have recommended terminology for such therapies that is consistent with other areas of medicine: prophylactic agents/protectors are agents that must be given before radiation exposure; mitigators are agents that are given after exposure, but before the appearance of overt evidence of injury; and treatment refers to agents that are given after overt symptoms develop (84). Agents with evidence for cardiac efficacy include free radical scavengers, antioxidants, statins, steroids, natural products, and other agents $(8,10,36,80,90)$.

In the present discussion, this will be limited to compounds that are potentially available to act as pharmaceutical and
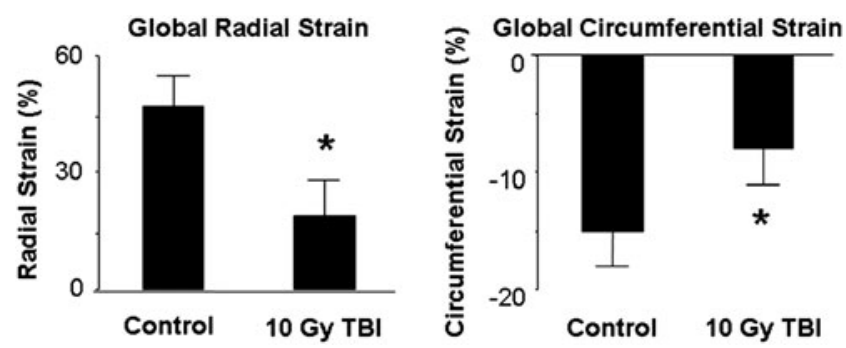

FIG. 6. Change in ventricular function at $\mathbf{1 2 0}$ days after 10 Gy TBI compared with age-matched controls. ${ }^{*} p<0.05$ for $10 \mathrm{~Gy}$ versus unirradiated age-matched control. Reproduced from Baker et al. (6) with permission from Taylor \& Francis, Ltd. (www.tandf.co.uk/journals). nutraceutical medical countermeasures against radiation-induced injury to the heart. The compounds discussed are not approved for use as mitigators of radiation-induced injury by the Food and Drug Administration (FDA). Design and development of novel pharmaceutical and nutraceuticals countermeasures against radiation-induced injury are outside the scope of this review.

\section{Vascular endothelium}

The vascular endothelium is believed to be a target for radiation-induced injury. The endothelium is the sentry against cardiovascular disease. It plays a pivotal role in vascular tone and remodeling as well as regulating thrombosis and inflammation. The thrombotic and inflammatory pathways are regulated by nitric oxide produced from endothelial nitric oxide synthase, thrombin, and the thrombin receptor (PAR1), and fibrinogen among other factors. Nitric oxide, through its anti-inflammatory and antithrombotic effects, is able to diminish leukocyte adhesion and arterial thrombosis. Nitric oxide and thrombosis have an intricate relationship. Nitric oxide decreases thrombosis by inhibiting the expression of the prothrombotic protein plasminogen activator inhibitor-1 and decreasing platelet aggregation (60), whereas thrombin enhances nitric oxide production through the thrombin receptor (43). Moreover, long-term exposure of endothelial cells (ECs) to thrombin results in a downregulation of endothelial nitric oxide synthase (35). Thrombin and endothelial PAR1 also contribute to the expression of inflammatory cytokines and adhesion molecules, and after leukocyte adhesion, their migration into tissue $(50,64,71)$. Fibrinogen, a protein secreted by the liver, is a key component of the coagulation cascade and functions at the level of the endothelium not only to promote thrombosis, but also to upregulate the inflammatory response. Elevated fibrinogen is correlated with an inflammatory state and the progression of atherosclerosis (73). EC damage and/or cell loss after radiation is likely to disrupt the anti-inflammatory and antithrombotic mechanisms, thereby promoting tissue damage and fibrosis through inflammatory and thrombotic mechanisms. Nitric oxide, thrombin, and PAR1 are central in this role. Thus, pharmaceutical and nutriceutical countermeasures directed toward maintaining endothelial function, especially by normalizing nitric oxide production and PAR1 expression, have potential to both mitigate and treat radiation-induced injury to the heart.

\section{Angiotensin-converting enzyme inhibitors}

The angiotensin-converting enzyme (ACE) inhibitor captopril, given after radiation exposure, mediates against structural changes to the heart after radiation (20 Gy), but is unable to prevent the decline in cardiac function (102). However, the effect of captopril with the lower levels of radiation associated with either a terrorist exploding a radiological device or as a nuclear accident on subsequent injury to the heart is unknown. Captopril also mediates radiationinduced renal injury (65). These ACE inhibitors are strong candidates for further evaluation in rats exposed to lower doses of irradiation, for example, $10 \mathrm{~Gy}$.

\section{Statins}

The vascular endothelium is a major effector compartment for the pleiotropic effects of statins, many of which appear to 
be related to the ability of statins to prevent the development of EC dysfunction during various disease states. Maintaining an anticoagulant cell surface is a critical aspect of endothelial function, and ensures not only thrombo-hemorrhagic homeostasis, but also the appropriate regulation of inflammatory and fibro-proliferative responses. Considerable research has focused on the mechanisms by which statins enhance endothelial anticoagulant and fibrinolytic properties. These studies show that statins increase the expression and enhance the activity of endothelial nitric oxide synthase (54), upregulate prostacyclin (76) and tissue-type plasminogen activator (34), decrease oxidative stress (72), and downregulate thrombin receptor expression (49).

Simvastatin is a prodrug of a specific inhibitor of 3-hydroxy-3-methylglutaryl-coenzyme A (HMG-CoA) reductase (29). Simvastatin is able to decrease lipid levels in blood. Moreover, simvastatin has recently been shown to be capable of decreasing radiation-induced injury to rats. Administration of dietary simvastatin for 1 year significantly decreased the incidence $(36 \%)$ of radiation-induced mammary tumors compared with that of the control rats (88\%) (48). Also, the development of adenocarcinoma in the simvastatin-fed rats was significantly reduced compared to that in the control rats. Simvastatin is also effective in reducing radiation-induced brain injury (S. Brown, pers. comm.). There have been no studies on the ability of simvastatin to ameliorate radiationinduced injury to the heart.

Vascular injury is believed to be a key factor in the pathogenesis of radiation-induced sclerosis, fibrosis, and thrombosis, but only recently have studies proposed a link between the persistence of endothelial dysfunction and radiation pathologies $(33,62,82,96)$. Radiation induces an early and sustained activation of vascular ECs $(39,40,92)$, resulting in maintenance of the functional pro-inflammatory and thrombogenic properties of these cells $(40,94)$. The slow loss of ECs after irradiation can invoke a change in EC function including the increased expression of adhesion molecules. Because it has been proposed that there may be indications for statins in conditions with endothelial dysfunction $(11,97)$, statins may improve endothelial function after radiation exposure. Pravastatin inhibits radiation-induced increases in the production of IL6, IL8, and MCP1 and the expression of ICAM1 by ECs, thus providing additional evidence for the anti-inflammatory properties of statins on EC. There have been no studies on the ability of pravastatin to treat radiation-induced injury to the heart.

\section{Curcumin}

Curcumin is a natural tropical plant polyphenol compound derived from the Curcuma longa Linn, a root related to Ginger. It is commonly found as a food additive and in the spice turmeric. Curcumin is a deep yellow pigment, and is responsible for the color found in South Asian curries as well as American yellow mustard, and has been an ingredient used in cooking since 600 B.C. Powdered turmeric is widely available in supermarkets throughout the United States as a household spice. The major pigment found in turmeric is curcumin (diferuloymethane), which is now known to possess pharmacologic anti-inflammatory and antioxidant properties. The Curcumin content of turmeric spice may range from 189 to $250 \mathrm{mg} / \mathrm{g}$ (i.e., $18 \%-25 \%$ of turmeric by weight) (77). Curcu- min has been used for hundreds of years as a component of Ayurvedic medicines, as a dietary supplement known to help gastrointestinal ailments, inflammatory lesions of the skin, and as an exfoliant. Western medical interest in the compound has increased dramatically after the discovery of the potent effect of curcumin as an inhibitor of NFKB and of the mitogenactivated protein kinases. There are over 20 clinical trials of curcumin currently registered at clinicaltrials.gov (Web site reference www.clinicaltrials.gov). Mammary and pituitary tumors in rats induced by radiation can be inhibited by curcimin administered after radiation exposure (47). However, there have been no studies on the ability of curcumin to ameliorate radiation-induced injury to the heart.

\section{Nitric oxide}

The reduction in nitric oxide generation as a result of dysfunctional vascular endothelium contributes to cardiovascular disease. Continuous generation of nitric oxide is essential to the survival and function of the heart, and decreased production of nitric oxide is central to the development of cardiovascular diseases $(42,46)$. Nitrite is a major storage form of nitric oxide $(\bullet \mathrm{NO})$ in blood and tissues (14). Oral nitrite reverses $N^{\mathrm{G}}$-nitro-L-arginine methyl ester-induced hypertension and serves as an alternate source of $\bullet \mathrm{NO}$ in vivo (91). Further, plasma nitrite levels progressively decrease with increasing cardiovascular risk (52). Nitrite is currently undergoing clinical trials to increase nitric oxide in patients with coronary artery disease (ClinicalTrials.gov identifier NCT00069654). Because a substantial portion of steady-state nitrite concentrations in blood and tissue are derived from dietary sources (15), modulation of nitrite intake may provide a first-line defense against radiation-induced injury. However, there is no experimental evidence indicating the consequences of dietary nitrite supplementation on risk factors for cardiovascular disease after radiation exposure.

\section{Conclusion}

Humans are continually exposed to radiation from terrestrial sources. On the Earth most human radiation exposures (medical and natural background) are from low LET photons (low LET $X$ - and $\gamma$-rays), low energy $\alpha$-particles from radon, and $\gamma$-rays and neutrons in the survivors of atomic bomb explosions. Diagnostic and therapeutic applications of radiation are widespread, and threats from radiological terrorism and nuclear power plants persist. These sources of radiation may increase risk for developing cardiovascular disease. Health risks associated with exposure to radiation exposure from deep space radiation will persist after astronauts return to the Earth as cardiovascular changes develop at long periods after exposure. For example, cardiovascular injury was observed in Japanese atomic bomb survivors at doses as low as $0.5-2.0 \mathrm{~Gy}$ to the entire body, doses lower than those normally associated with cardiac injury if the exposure dose is localized to the thorax or heart. The risk of developing cardiovascular disease in patients exposed to radiation for diagnostic and therapeutic purposes, and from occupational radiation exposure remains a health concern. Further studies are needed to define the mechanisms underlying injury to the cardiovascular system from exposure to terrestrial and cosmic radiation, and to develop strategies for mitigation and treatment of radiation-induced injury. 


\section{Acknowledgment}

This work was supported in part by cooperative agreement AI067734 and grants HL54075 and AI080363 from the National Institutes of Health.

\section{References}

1-3. These references have been deleted.

4. Adams MJ, Lipshultz SE, Schwartz C, Fajardo LF, Coen V, and Constine LS. Radiation-associated cardiovascular disease: manifestations and management. Semin Radiat Oncol 13: 346-356, 2003.

5. Alpen EL, Powers-Risius P, Curtis SB, and DeGuzman R. Tumorigenic potential of high-Z, high-LET charged-particle radiations. Radiat Res 136: 382-391, 1993.

6. Baker JE, Fish B, Su J, Haworth S, Strande J, Komorowski R, Migrino R, Doppalapudi A, Harmann L, Li X, Hopewell J, and Moulder J. 10 Gy Total body irradiation increases risk of coronary sclerosis, degeneration of heart structure and function in a rat model. Int J Radiat Biol 85: 1089-1100, 2009.

7. Barrett-Connor E. Sex differences in coronary heart disease. Why are women so superior? The 1995 Ancel Keys Lecture. Circulation 95: 252-264, 1997.

8. Beller CJ, Radovits T, Seres L, Kosse J, Krempien R, Gross ML, Penzel R, Berger I, Huber PE, Hagl S, Szabo C, and Szabo G. Poly(ADP-ribose) polymerase inhibition reverses vascular dysfunction after gamma-irradiation. Int J Radiat Oncol Biol Phys 65: 1528-1535, 2006.

9. Boerma M, Kruse JJ, van Loenen M, Klein HR, Bart CI, Zurcher $\mathrm{C}$, and Wondergem J. Increased deposition of von Willebrand factor in the rat heart after local ionizing irradiation. Strahlenther Onkol 180: 109-116, 2004.

10. Boerma M, Roberto KA, and Hauer-Jensen M. Prevention and treatment of functional and structural radiation injury in the rat heart by pentoxifylline and alpha-tocopherol. Int $J$ Radiat Oncol Biol Phys 71: 170-177, 2008.

11. Bonetti PO, Lerman LO, Napoli C, and Lerman A. Statin effects beyond lipid lowering-are they clinically relevant? Eur Heart J 24: 225-248, 2003.

12. Brenner DJ and Hall EJ. Computed tomography-an increasing source of radiation exposure. N Engl J Med 357: 2277-2284, 2007.

13. This reference has been deleted.

14. Bryan NS. Nitrite in nitric oxide biology: cause or consequence? A systems-based review. Free Radic Biol Med 41: 691-701, 2006.

15. Bryan NS, Fernandez BO, Bauer SM, Garcia-Saura MF, Milsom AB, Rassaf T, Maloney RE, Bharti A, Rodriguez J, and Feelisch M. Nitrite is a signaling molecule and regulator of gene expression in mammalian tissues. Nat Chem Biol 1: 290-297, 2005.

16. Burns FJ, Jin Y, Koenig KL, and Hosselet S. The low carcinogenicity of electron radiation relative to argon ions in rat skin. Radiat Res 135: 178-188, 1993.

17. Carr ZA, Land CE, Kleinerman RA, Weinstock RW, Stovall M, Griem ML, and Mabuchi K. Coronary heart disease after radiotherapy for peptic ulcer disease. Int J Radiat Oncol Biol Phys 61: 842-850, 2005.

18. Cilliers GD, Harper IS, and Lochner A. Radiation-induced changes in the ultrastructure and mechanical function of the rat heart. Radiother Oncol 16: 311-326, 1989.
19. Clarke M, Collins R, Darby S, Davies C, Elphinstone P, Evans E, Godwin J, Gray R, Hicks C, James S, MacKinnon E, McGale P, McHugh T, Peto R, Taylor C, and Wang Y. Effects of radiotherapy and of differences in the extent of surgery for early breast cancer on local recurrence and 15year survival: an overview of the randomised trials. Lancet 366: 2087-2106, 2005.

20. Cohen EP. Radiation nephropathy after bone marrow transplantation. Kidney Int 58: 903-918, 2000.

21. Cohn KE, Stewart JR, Fajardo LF, and Hancock EW. Heart disease following radiation. Medicine (Baltimore) 46: 281298, 1967.

22. Coleman CN, Blakely WF, Fike JR, MacVittie TJ, Metting NF, Mitchell JB, Moulder JE, Preston RJ, Seed TM, Stone HB, Tofilon PJ, and Wong RS. Molecular and cellular biology of moderate-dose (1-10 Gy) radiation and potential mechanisms of radiation protection: report of a workshop at Bethesda, Maryland, December 17-18, 2001. Radiat Res 159: 812-834, 2003

23. Cucinotta F, Kim M, and Ren L. Managing Luncar and Mars Mission Radiation Risks, Part I: Cancer Risks, Uncertainties, and Shielding Effectiveness, edited by NASA/TP-2005213164. Washington, DC: NASA, 2005, p. 18.

24. Cucinotta FA, Nikjoo H, and Goodhead DT. The effects of delta rays on the number of particle-track traversals per cell in laboratory and space exposures. Radiat Res 150: 115-119, 1998.

25. Cucinotta FA, Schimmerling W, Wilson JW, Peterson LE, Badhwar GD, Saganti PB, and Dicello JF. Space radiation cancer risks and uncertainties for Mars missions. Radiat Res 156: 682-688, 2001.

26. Curtis SB, Vazquez M, Wilson JW, Atwell W, Kim M, and Capala J. Cosmic hit frequencies in critical sites in the central nervous system. Adv Space Res 12: 197-207, 1998.

27. Darby S, McGale P, Peto R, Granath F, Hall P, and Ekbom A. Mortality from cardiovascular disease more than 10 years after radiotherapy for breast cancer: nationwide cohort study of 90000 Swedish women. BMJ 326: 256-257, 2003.

28. Darby SC, McGale P, Taylor CW, and Peto R. Long-term mortality from heart disease and lung cancer after radiotherapy for early breast cancer: prospective cohort study of about 300,000 women in US SEER cancer registries. Lancet Oncol 6: 557-565, 2005.

29. Del Puppo M, Rauli S, and Galli Kienle M. Inhibition of cholesterol synthesis and hepatic 3-hydroxy-3-methylglutaryl-CoA reductase in rats by simvastatin and pravastatin. Lipids 30: 1057-1061, 1995.

30. Dicello JF, Christian A, Cucinotta FA, Gridley DS, Kathirithamby R, Mann J, Markham AR, Moyers MF, Novak GR, Piantadosi S, Ricart-Arbona R, Simonson DM, Strandberg JD, Vazquez M, Williams JR, Zhang Y, Zhou H, and Huso D. In vivo mammary tumourigenesis in the SpragueDawley rat and microdosimetric correlates. Phys Med Biol 49: 3817-3830, 2004.

31. Durante M and Kronenberg A. Ground-based research with heavy ions for space radiation protection. Adv Space Res 35: 180-184, 2005.

32. Eames GM, Crosson J, Steinberger J, Steinbuch M, Krabill K, Bass J, Ramsay NK, and Neglia JP. Cardiovascular function in children following bone marrow transplant: a crosssectional study. Bone Marrow Transplant 19: 61-66, 1997.

33. Epperly MW, Sikora CA, DeFilippi SJ, Gretton JE, Bar-Sagi D, Archer H, Carlos T, Guo H, and Greenberger JS. Pulmonary irradiation-induced expression of VCAM-I and 
ICAM-I is decreased by manganese superoxide dismutaseplasmid/liposome (MnSOD-PL) gene therapy. Biol Blood Marrow Transplant 8: 175-187, 2002.

34. Essig M, Nguyen G, Prie D, Escoubet B, Sraer JD, and Friedlander G. 3-Hydroxy-3-methylglutaryl coenzyme A reductase inhibitors increase fibrinolytic activity in rat aortic endothelial cells. Role of geranylgeranylation and Rho proteins. Circ Res 83: 683-690, 1998.

35. Eto M, Barandier C, Rathgeb L, Kozai T, Joch H, Yang Z, and Luscher TF. Thrombin suppresses endothelial nitric oxide synthase and upregulates endothelin-converting enzyme-1 expression by distinct pathways: role of Rho/ ROCK and mitogen-activated protein kinase. Circ Res 89: 583-590, 2001.

36. Evans ML, Graham MM, Mahler PA, and Rasey JS. Use of steroids to suppress vascular response to radiation. Int J Radiat Oncol Biol Phys 13: 563-567, 1987.

37. Fajardo LF and Stewart JR. Experimental radiation-induced heart disease. I. Light microscopic studies. Am J Pathol 59: 299-316, 1970.

38. Fliedner TM, D Dorr H, and Meineke V. Multi-organ involvement as a pathogenetic principle of the radiation syndromes: a study involving 110 case histories documented in SEARCH and classified as the bases of haematopoietic indicators of effect. BJR Suppl 27: 1-8, 2005.

39. Gaugler MH, Squiban C, Mouthon MA, Gourmelon P, and van der Meeren A. Irradiation enhances the support of haemopoietic cell transmigration, proliferation and differentiation by endothelial cells. Br J Haematol 113: 940-950, 2001.

40. Gaugler MH, Squiban C, van der Meeren A, Bertho JM, Vandamme M, and Mouthon MA. Late and persistent upregulation of intercellular adhesion molecule-1 (ICAM-1) expression by ionizing radiation in human endothelial cells in vitro. Int J Radiat Biol 72: 201-209, 1997.

41. Helfand I, Forrow L, and Tiwari J. Nuclear terrorism. BMJ 324: 356-359, 2002.

42. Herman AG and Moncada S. Therapeutic potential of nitric oxide donors in the prevention and treatment of atherosclerosis. Eur Heart J 26: 1945-1955, 2005.

43. Hirano K, Nomoto N, Hirano M, Momota F, Hanada A, and Kanaide H. Distinct Ca2 + Requirement for NO production between proteinase-activated receptor 1 and 4 (PAR1 and PAR4) in vascular endothelial cells. J Pharmacol Exp Ther 322: 668-677, 2007.

44. Holdstock D and Waterston L. Nuclear weapons, a continuing threat to health. Lancet 355: 1544-1547, 2000.

45. Hooning MJ, Botma A, Aleman BM, Baaijens MH, Bartelink $\mathrm{H}$, Klijn JG, Taylor CW, and van Leeuwen FE. Long-term risk of cardiovascular disease in 10-year survivors of breast cancer. J Natl Cancer Inst 99: 365-375, 2007.

46. Ignarro LJ. Nitric oxide as a unique signaling molecule in the vascular system: a historical overview. J Physiol Pharmacol 53: 503-514, 2002.

47. Inano $\mathrm{H}$ and Onoda M. Radioprotective action of curcumin extracted from Curcuma longa LINN: inhibitory effect on formation of urinary 8-hydroxy-2'-deoxyguanosine, tumorigenesis, but not mortality, induced by gammaray irradiation. Int J Radiat Oncol Biol Phys 53: 735-743, 2002.

48. Inano H, Suzuki K, Onoda M, and Wakabayashi K. Anticarcinogenic activity of simvastatin during the promotion phase of radiation-induced mammary tumorigenesis of rats. Carcinogenesis 18: 1723-1727, 1997.
49. Jacobson JR, Dudek SM, Birukov KG, Ye SQ, Grigoryev DN, Girgis RE, and Garcia JGN. Cytoskeletal activation and altered gene expression in endothelial barrier regulation by simvastatin. Am J Respir Cell Mol Biol 30: 662-670, 2004.

50. Johnson K, Choi Y, DeGroot E, Samuels I, Creasey A, and Aarden L. Potential mechanisms for a proinflammatory vascular cytokine response to coagulation activation. J Immunol 160: 5130-5135, 1998.

51. King V, Constine LS, Clark D, Schwartz RG, Muhs AG, Henzler M, Hutson A, and Rubin P. Symptomatic coronary artery disease after mantle irradiation for Hodgkin's disease. Int J Radiat Oncol Biol Phys 36: 881-889, 1996.

52. Kleinbongard P, Dejam A, Lauer T, Jax T, Kerber S, Gharini P, Balzer J, Zotz RB, Scharf RE, Willers R, Schechter AN, Feelisch M, and Kelm M. Plasma nitrite concentrations reflect the degree of endothelial dysfunction in humans. Free Radic Biol Med 40: 295-302, 2006.

53. Kruse JJ, Zurcher C, Strootman EG, Bart CI, Schlagwein N, Leer JW, and Wondergem J. Structural changes in the auricles of the rat heart after local ionizing irradiation. Radiother Oncol 58: 303-311, 2001.

54. Laufs U, La Fata V, Plutzky J, and Liao JK. Upregulation of endothelial nitric oxide synthase by HMG CoA reductase inhibitors. Circulation 97: 1129-1135, 1998.

55. Lauk S. Strain differences in the radiation response of the rat heart. Radiother Oncol 5: 333-335, 1986.

56. Lauk S, Kiszel Z, Buschmann J, and Trott KR. Radiationinduced heart disease in rats. Int J Radiat Oncol Biol Phys 11: 801-808, 1985.

57. Lee CK, Aeppli D, and Nierengarten ME. The need for long-term surveillance for patients treated with curative radiotherapy for Hodgkin's disease: University of Minnesota experience. Int J Radiat Oncol Biol Phys 48: 169-179, 2000.

58. Leiper AD. Late effects of total body irradiation. Arch Dis Child 72: 382-385, 1995.

59. Little MP, Tawn EJ, Tzoulaki I, Wakeford R, Hildebrandt G, Paris F, Tapio S, and Elliott P. A systematic review of epidemiological associations between low and moderate doses of ionizing radiation and late cardiovascular effects, and their possible mechanisms. Radiat Res 169: 99-109, 2008.

60. Loscalzo J. Nitric oxide insufficiency, platelet activation, and arterial thrombosis. Circ Res 88: 756-762, 2001.

61. Meacham L, Chow E, Ness K, Kamdar K, Chen Y, Yasui Y, Oeffinger K, Sklar C, Robison L, and Mertens A. Cardiovascular risk factors in adult survivors of pediatric cancer-a report from the childhood cancer survivor study. Cancer Epidemiol Biomarkers Prev 19: 170-181, 2010.

62. Molla M, Gironella M, Miquel R, Tovar V, Engel P, Biete A, Pique JM, and Panes J. Relative roles of ICAM-1 and VCAM-1 in the pathogenesis of experimental radiationinduced intestinal inflammation. Int J Radiat Oncol Biol Phys 57: 264-273, 2003.

63. Morin RL, Gerber TC, and McCollough CH. Radiation dose in computed tomography of the heart. Circulation 107: 917922, 2003.

64. Moser R, Groscurth P, and Fehr J. Promotion of transendothelial neutrophil passage by human thrombin. J Cell Sci 96 (Pt 4): 737-744, 1990.

65. Moulder JE, Fish BL, and Cohen EP. Treatment of radiation nephropathy with ACE inhibitors. Int J Radiat Oncol Biol Phys 27: 93-99, 1993. 
66. Mulrooney D, Yeazel M, Kawashima T, Mertens A, Mitby P, Stovall M, Donaldson S, Green D, Sklar C, Robison L, and Lesenring W. Cardiac outcomes in a cohort of adult survivors of childhood and adolescent cancer: retrospective analysis of the childhood cancer survivor study cohort. BMJ 340: 34-44, 2010.

67. Paszat LF, Mackillop WJ, Groome PA, Schulze K, and Holowaty E. Mortality from myocardial infarction following postlumpectomy radiotherapy for breast cancer: a population-based study in Ontario, Canada. Int J Radiat Oncol Biol Phys 43: 755-762, 1999.

68. Pihkala J, Saarinen UM, Lundstrom U, Salmo M, Virkola K, Virtanen K, Siimes MA, and Pesonen E. Effects of bone marrow transplantation on myocardial function in children. Bone Marrow Transplant 13: 149-155, 1994.

69. Plowman N. A review of total body irradiation. Br J Radiol 22: 135-145, 1987.

70. Preston DL, Shimizu Y, Pierce DA, Suyama A, and Mabuchi K. Studies of mortality of atomic bomb survivors. Report 13: Solid cancer and noncancer disease mortality: 1950-1997. Radiat Res 160: 381-407, 2003.

71. Rahman A, Anwar KN, True AL, and Malik AB. Thrombininduced p65 homodimer binding to downstream NF-kappa B site of the promoter mediates endothelial ICAM-1 expression and neutrophil adhesion. J Immunol 162: 5466-5476, 1999.

71a. Report of the United Nations Scientific Committee on the Effects of Atomic Radiation. 2008 pp. ISSN 0255-1372.

72. Rikitake Y, Kawashima S, Takeshita S, Yamashita T, Azumi H, Yasuhara M, Nishi H, Inoue N, and Yokoyama M. Antioxidative properties of fluvastatin, an HMG-CoA reductase inhibitor, contribute to prevention of atherosclerosis in cholesterol-fed rabbits. Atherosclerosis 154: 87-96, 2001.

73. Sabeti S, Exner M, Mlekusch W, Amighi J, Quehenberger P, Rumpold H, Maurer G, Minar E, Wagner O, and Schillinger M. Prognostic impact of fibrinogen in carotid atherosclerosis: nonspecific indicator of inflammation or independent predictor of disease progression? Stroke 36: 1400-1404, 2005.

74. Schimmerling $\mathrm{W}$ and Cucinotta FA. Dose and dose rate effectiveness of space radiation. Radiat Prot Dosimetry 122: 349-353, 2006.

75. Schultz-Hector S and Trott KR. Radiation-induced cardiovascular diseases: is the epidemiologic evidence compatible with the radiobiologic data? Int J Radiat Oncol Biol Phys 67: 10-18, 2007.

76. Seeger H, Mueck AO, and Lippert TH. Fluvastatin increases prostacyclin and decreases endothelin production by human umbilical vein endothelial cells. Int J Clin Pharmacol Ther 38: 270-272, 2000.

77. Shankariah V, Fernando L, and Guren I. Curcumin content and heat effect on curcumin in turmeric samples. International Food Technologies Annual Meeting. New Orleans, LA, 2001.

78. Sharma A, Wong D, Weidlich G, Fogarty T, Jack A, Sumanaweera $\mathrm{T}$, and Maguire $\mathrm{P}$. Noninvasive stereotactic radiosurgery (CyberHeart) for creation of ablation lesions in the atrium. Heart Rhythm 7: 802-810, 2010.

79. Shimizu Y, Kodama K, Nishi N, Kasagi F, Suyama A, Soda M, Grant EJ, Sugiyama H, Sakata R, Moriwaki H, Hayashi M, Konda M, and Shore RE. Radiation exposure and circulatory disease risk: Hiroshima and Nagasaki atomic bomb survivor data, 1950-2003. BMJ 340: b5349, 2010.

80. Soucy KG, Lim HK, Attarzadeh DO, Santhanam L, Kim JH, Bhunia AK, Sevinc B, Ryoo S, Vazquez ME, Nyhan D, Shoukas AA, and Berkowitz DE. Dietary inhibition of xanthine oxidase attenuates radiation-induced endothelial dysfunction in rat aorta. J Appl Physiol 108: 1250-1258, 2010.

80a. Sources and Effects of Ionizing Radiation. UNSCEAR 2000 Reports, Volumes I and II. New York: UNSCEAR, 2000.

81. Stewart FA, Hoving S, and Russell NS. Vascular damage as an underlying mechanism of cardiac and cerebral toxicity in irradiated cancer patients. Radiat Res 174: 865-869, 2010.

82. Stewart FA, Te Poele JA, Van der Wal AF, Oussoren YG, Van Kleef EM, Kuin A, Verheij M, and Dewit LG. Radiation nephropathy-the link between functional damage and vascular mediated inflammatory and thrombotic changes. Acta Oncol 40: 952-957, 2001.

83. Stewart JR and Fajardo LF. Radiation-induced heart disease: an update. Prog Cardiovasc Dis 27: 173-194, 1984.

84. Stone HB, Moulder JE, Coleman CN, Ang KK, Anscher MS, Barcellos-Hoff MH, Dynan WS, Fike JR, Grdina DJ, Greenberger JS, Hauer-Jensen M, Hill RP, Kolesnick RN, Macvittie TJ, Marks C, McBride WH, Metting N, Pellmar T, Purucker M, Robbins ME, Schiestl RH, Seed TM, Tomaszewski JE, Travis EL, Wallner PE, Wolpert M, and Zaharevitz D. Models for evaluating agents intended for the prophylaxis, mitigation and treatment of radiation injuries. Report of an NCI workshop, December 3-4, 2003. Radiat Res 162: 711-728, 2004.

85. Stoney CM, Davis MC, and Matthews KA. Sex differences in physiological responses to stress and in coronary heart disease: a causal link? Psychophysiology 24: 127-131, 1987.

86. Straume T, Rugel G, Marchetti AA, Ruhm W, Korschinek G, McAninch JE, Carroll K, Egbert S, Faestermann T, Knie K, Martinelli R, Wallner A, and Wallner C. Measuring fast neutrons in Hiroshima at distances relevant to atomicbomb survivors. Nature 424: 539-542, 2003.

87. Swerdlow AJ, Higgins CD, Smith P, Cunningham D, Hancock BW, Horwich A, Hoskin PJ, Lister A, Radford JA, Rohatiner AZ, and Linch DC. Myocardial infarction mortality risk after treatment for Hodgkin disease: a collaborative British cohort study. J Natl Cancer Inst 99: 206-214, 2007.

88. Taylor CW, McGale P, Povall JM, Thomas E, Kumar S, Dodwell D, and Darby SC. Estimating cardiac exposure from breast cancer radiotherapy in clinical practice. Int $J$ Radiat Oncol Biol Phys 73: 1061-1068, 2009.

89. Taylor CW, Nisbet A, McGale P, and Darby SC. Cardiac exposures in breast cancer radiotherapy: 1950s-1990s. Int J Radiat Oncol Biol Phys 69: 1484-1495, 2007.

90. Tokatli F, Uzal C, Doganay L, Kocak Z, Kaya M, Ture M, Kurum T, Alkaya F, Karadag H, and Kutlu K. The potential cardioprotective effects of amifostine in irradiated rats. Int $J$ Radiat Oncol Biol Phys 58: 1228-1234, 2004.

91. Tsuchiya K, Kanematsu Y, Yoshizumi M, Ohnishi H, Kirima K, Izawa Y, Shikishima M, Ishida T, Kondo S, Kagami S, Takiguchi Y, and Tamaki T. Nitrite is an alternative source of NO in vivo. Am J Physiol Heart Circ Physiol 288: H2163-H2170, 2005.

91a. United Nations Scientific Committee on the Effects of Atomic Radiation (UNSCEAR). Sources and Effects of Ionizing Radiation. UNSCEAR 2000 Report to the General Assembly, with Scientific Annexes. Volume I: Sources. New York: United Nations, 2000.

92. Van der Meeren A, Vandamme M, Squiban C, Gaugler MH, and Mouthon MA. Inflammatory reaction and changes in expression of coagulation proteins on lung endothelial cells after total-body irradiation in mice. Radiat Res 160: 637-646, 2003. 
93. van der Pal HJ, van Dalen EC, Kremer LC, Bakker PJ, and van Leeuwen FE. Risk of morbidity and mortality from cardiovascular disease following radiotherapy for childhood cancer: a systematic review. Cancer Treat Rev 31: 173185, 2005.

94. Vereycken-Holler V, Aigueperse J, and Gaugler MH. Radiation effects on circulating and endothelial cell interactions studied by real-time videomicroscopy. Int J Radiat Biol 78: 923-930, 2002.

95. Villasana L, Rosenberg J, and Raber J. Sex-dependent effects of $56 \mathrm{Fe}$ irradiation on contextual fear conditioning in C57BL/6J mice. Hippocampus 20: 19-23, 2010.

96. Wang J, Zheng H, Ou X, Fink LM, and Hauer-Jensen M. Deficiency of microvascular thrombomodulin and up-regulation of protease-activated receptor-1 in irradiated rat intestine: possible link between endothelial dysfunction and chronic radiation fibrosis. Am J Pathol 160: 2063-2072, 2002.

97. Wolfrum S, Jensen KS, and Liao JK. Endothelium-dependent effects of statins. Arterioscler Thromb Vasc Biol 23: 729 736, 2003.

98. Wondergem J, van der Laarse A, van Ravels FJ, van Wermeskerken AM, Verhoeve HR, de Graaf BW, and Leer JW. In vitro assessment of cardiac performance after irradiation using an isolated working rat heart preparation. Int J Radiat Biol 59: 1053-1068, 1991.

99. Yamada M, Wong FL, Fujiwara S, Akahoshi M, and Suzuki G. Noncancer disease incidence in atomic bomb survivors, 1958-1998. Radiat Res 161: 622-632, 2004.

100. Yang VC. Late structural changes in mouse coronary arteries after iron-particle irradiation of the orbital region. Radiat Res 134: 390-393, 1993.

101. Yang VV and Ainsworth EJ. Late effects of heavy charged particles on the fine structure of the mouse coronary artery. Radiat Res 91: 135-144, 1982.

102. Yarom R, Harper IS, Wynchank S, van Schalkwyk D, Madhoo J, Williams K, Salie R, Genade S, and Lochner A. Effect of captopril on changes in rats' hearts induced by long-term irradiation. Radiat Res 133: 187-197, 1993.

103. Yeung TK and Hopewell JW. Effects of single doses of radiation on cardiac function in the rat. Radiother Oncol 3: 339-345, 1985.

104. Yeung TK, Lauk S, Simmonds RH, Hopewell JW, and Trott KR. Morphological and functional changes in the rat heart after X irradiation: strain differences. Radiat Res 119: 489_ 499, 1989.

105. Yochmowitz MG, Wood DH, and Salmon YL. Seventeenyear mortality experience of proton radiation in Macaca mulatta. Radiat Res 102: 14-34, 1985.

Address correspondence to: Dr. John E. Baker Division of Cardiothoracic Surgery Medical College of Wisconsin 8701 Watertown Plank Road Milwaukee, WI 53226

E-mail: jbaker@mcw.edu

Date of first submission to ARS Central, October 27, 2010; date of acceptance, November 21, 2010.

$\begin{aligned} & \text { Abbreviations Used } \\ 2 \mathrm{p}= & \text { two sided } p \text {-value } \\ \mathrm{ACE}= & \text { angiotensin-converting enzyme } \\ \mathrm{CI}= & \text { confidence interval } \\ \mathrm{CT}= & \text { computed tomography } \\ \mathrm{EBCTCG}= & \text { Early Breast Trialists' Collaborative } \\ & \quad \text { Group } \\ \mathrm{EC}= & \text { endothelial cells } \\ \mathrm{FDA} & =\text { Food and Drug Administration } \\ \mathrm{GCR}= & \text { galactic cosmic rays } \\ \mathrm{Gy}= & \text { gray } \\ \mathrm{HMG}= & \text { high energy } \\ \mathrm{HAEA}= & \text { International Atomic Energy Agency } \\ \mathrm{LET}= & \text { linear energy transfer } \\ \mathrm{NO}= & \text { nitric oxide } \\ \mathrm{OR}= & \text { odds ratio } \\ \mathrm{Sv}= & \text { sievert } \\ \mathrm{SPE}= & \text { solar particle events } \\ \mathrm{TBI}= & \text { total body irradiation } \\ \mathrm{U} . \mathrm{S} . \mathrm{SEER}= & \text { U.S. Surveillance Epidemiology and } \\ & \text { End Result }\end{aligned}$

